\title{
Ferroelastic oligocrystalline microwire with unprecedented high-temperature superelastic and shape memory effects
}

Zhen Chen', Daoyong Cong $\mathbb{D}^{1}$, Yang Ren $\mathbb{D}^{2,3}$, Yin Zhang ${ }^{1}$, Haile Yan ${ }^{4}$, Li You', Chao Song ${ }^{1}$, Shaohui Li', Yuxian Cao', Shengwei $\mathrm{Li}^{1}$, Changchang Zuo', Li Wang', Zhiyong Gao ${ }^{5}$, Wei Cai ${ }^{5}$ and Yandong Wang ${ }^{1}$

\begin{abstract}
A compelling demand exists for high-performance high-temperature shape memory alloys (HTSMAs) that can be applied as intelligent components in the rapidly developing aerospace, robotics, manufacturing, and energy exploration industries. However, existing HTSMAs are handicapped by their high cost and unsatisfactory functional properties, which impede their practical application. Here, by using the strategy of creating an oligocrystalline structure, we have developed a high-performance, cost-effective high-temperature shape memory microwire exhibiting an exceptional combination of superb superelasticity with a large recoverable strain of up to $15 \%$, an outstanding one-way shape memory effect with a maximum recoverable strain as high as $13 \%$ and a remarkable two-way shape memory effect with a large recoverable strain of $6.3 \%$. These unparalleled comprehensive properties provide this microwire with a high potential for use in high-temperature actuation, sensing, and energy conversion applications, especially in miniature intelligent devices, such as high-temperature microelectromechanical systems. The present strategy may be universally applicable to other brittle phase-transforming alloys for achieving outstanding functional properties at high temperatures.
\end{abstract}

\section{Introduction}

There exists a compelling need for high-performance high-temperature shape memory alloys (HTSMAs) ${ }^{1-5}$ that can be applied as intelligent components at elevated temperatures in the rapidly developing aerospace, robotics, manufacturing, and energy exploration industries. These HTSMAs, which are a class of ferroelastic materi$\mathrm{als}^{6}$, can be used as compact, efficient solid-state actuators, sensors, and energy conversion devices in rocket motors, jet engines, and gas turbines that have operating temperatures higher than $100^{\circ} \mathrm{C}^{2,4,7}$. Compared with commercial pneumatic, hydraulic or motor-driven

Correspondence: Daoyong Cong (dycong@ustb.edu.cn)

${ }^{1}$ Beijing Advanced Innovation Center for Materials Genome Engineering, State Key Laboratory for Advanced Metals and Materials, University of Science and Technology Beijing, Beijing 100083, China

${ }^{2}$ X-ray Science Division, Argonne National Laboratory, Argonne, IL 60439, USA Full list of author information is available at the end of the article systems, HTSMA-based solid-state intelligent components possess the advantages of a high energy density, compactness, a light weight, system simplicity ${ }^{8}$, and silent operation; thus, these components have attracted increasing attention in recent decades.

Enormous efforts have recently been made to develop high-performance HTSMAs ${ }^{7-14}$. However, the prevailing $\mathrm{Ti}-\mathrm{Ni}-(\mathrm{Pt} / \mathrm{Pd} / \mathrm{Au} / \mathrm{Hf})$ alloys are quite expensive owing to the high amounts of constituent $\mathrm{Pt}, \mathrm{Pd}, \mathrm{Au}$, or $\mathrm{Hf} ;{ }^{2,5,10}$ additionally, they show only a limited output strain (typically less than 5\%). Although single crystals of $\mathrm{Ni}-\mathrm{Mn}-\mathrm{Ga}$ alloys display improved functional performance ${ }^{15}$, producing single crystals is complicated and time-consuming, which results in high costs. Polycrystalline $\mathrm{Ni}-\mathrm{Mn}-\mathrm{Ga}$ alloys are extremely brittle ${ }^{16}$ and have inferior functional properties. The high cost and/or unsatisfactory functional properties of existing HTSMAs severely impede their practical application. Thus, the 
design of cost-effective, high-performance HTSMAs has been challenging for decades.

Here, we employ a strategy of creating an oligocrystalline structure to design high-performance HTSMAs. Polycrystals of intermetallic shape memory alloys often experience brittle intergranular fracture during ferroelastic martensitic phase transformation ${ }^{17-21}$ because stress concentrations usually form near grain boundaries and triple junctions due to the incompatibility of deviatoric strains associated with martensitic transformation at grain boundaries ${ }^{22,23}$. By forming the oligocrystalline structure, in which fewer grains with hardly any triple junctions exist and the total surface area exceeds the total grain boundary $\operatorname{area}^{23}$, the martensitic transformation occurs in a much less constrained environment ${ }^{24}$ by virtue of stress relaxation at free surfaces, and the strain incompatibilities between different grains are drastically reduced, suppressing intergranular fracture during transformation and contributing to extraordinary functional properties.

In this work, we produced an oligocrystalline structure in $\mathrm{Ni}-\mathrm{Mn}-\mathrm{Fe}-\mathrm{Ga}$ microwires by the Taylor-Ulitovsky method $^{25,26}$, which involves the quenching and drawing technique; notably, this strategy proves to be a feasible and cost-effective way to fabricate long, continuous microwires. The oligocrystalline $\mathrm{Ni}_{55} \mathrm{Mn}_{20} \mathrm{Fe}_{4} \mathrm{Ga}_{21}$ microwire exhibits superb tensile superelasticity with a large recoverable strain of up to $15 \%$ (three times that of archetypal $\mathrm{Ti}-\mathrm{Ni}-(\mathrm{Pt} / \mathrm{Pd} / \mathrm{Au} / \mathrm{Hf}) \mathrm{HTSMAs})$ at elevated temperatures of $270^{\circ} \mathrm{C}$ up to $480^{\circ} \mathrm{C}$, a notable one-way shape memory effect (SME) with a maximum recoverable strain of $13 \%$ (more than twice that of $\mathrm{Ti}-\mathrm{Ni}-(\mathrm{Pt} /$ $\mathrm{Pd} / \mathrm{Au} / \mathrm{Hf}) \mathrm{HTSMAs}$ ), and a large two-way SME with a recoverable strain of $6.3 \%$. Such exceptional comprehensive properties have never been reported in a single material. Microwires with such outstanding functional properties show tremendous potential for hightemperature actuation, sensing and energy conversion applications, especially in miniature devices, including microelectromechanical systems (MEMS). Furthermore, the present work provides a strategy for achieving superb high-temperature functional properties in ubiquitous brittle phase-transforming alloys.

\section{Materials and methods}

Polycrystalline $\mathrm{Ni}_{55} \mathrm{Mn}_{20} \mathrm{Fe}_{4} \mathrm{Ga}_{21}$ (at.\%) button ingots were prepared by arc melting using high-purity $\mathrm{Ni}, \mathrm{Fe}$, $\mathrm{Mn}$, and $\mathrm{Ga}$. The ingots were melted four times to ensure their homogeneous composition. Glass-coated microwires with diameters of approximately $120 \mu \mathrm{m}$ were prepared by the Taylor-Ulitovsky method ${ }^{25,26}$. The as-drawn microwires were directly tested after removing the glass sheath by grinding on fine sandpaper without any post heat treatments. The actual composition of the microwire was measured by an electron probe microanalyzer to be $\mathrm{Ni}_{55.7} \mathrm{Mn}_{18.8} \mathrm{Fe}_{4.3} \mathrm{Ga}_{21.2}$.

Differential scanning calorimetry (DSC) measurements were conducted with cooling and heating rates of $10^{\circ} \mathrm{C} /$ min to determine the phase transformation temperatures. $\mathrm{X}$-ray diffraction (XRD) using a $\mathrm{Cu} \mathrm{K}_{\alpha}$ radiation source $(\lambda=1.5406 \AA)$ was used to determine the crystal structure at room temperature. The microwires were closely placed in a region of $8 \times 8 \mathrm{~mm}^{2}$ on the platinum plate for XRD measurement, and a scan rate of $2 \% \mathrm{~min}$ was used. Electron backscatter diffraction (EBSD) measurements were performed at room temperature to examine the orientations of the martensitic variants. The microstructure was observed by scanning electron microscopy (SEM, Zeiss Supra55) and transmission electron microscopy (TEM, Tecnai F30) operated at $300 \mathrm{kV}$. The samples for TEM observation were prepared by argon ion-beam thinning using a Gatan Model 691 precision ion polishing system.

All mechanical tests were conducted in tension mode with a dynamic mechanical analyzer (DMA, TA Instruments Q800, with a maximum load of $18 \mathrm{~N}$ ) equipped with a closed furnace. The loaded force was measured at a high resolution of $10^{-5} \mathrm{~N}$ using a load cell, and the strain was recorded at a high resolution using a linear optical encoder with a resolution of $1 \mathrm{~nm}$. The superelasticity was examined by measuring the isothermal stress-strain curves at different temperatures in stress control mode. The one-way SME was studied by measuring the strain variation during constant stress thermal cycling across phase transformations at different stress levels. For each measurement, the microwire was first heated to a temperature $\left(T_{\mathrm{i}}\right)$ well above the austenitic transformation finish temperature $A_{\mathrm{f}}$, then stress was applied, and subsequently, the strain was measured during cooling to a temperature well below the martensitic transformation finish temperature $M_{\mathrm{f}}$ and subsequent heating back to $T_{\mathrm{i}}$; at the end of the measurement, the stress was released at $T_{\mathrm{i}}$. The two-way shape memory effect (TWSME) was investigated by measuring the strain variation during cooling and heating across the phase transformation with a tiny stress of $0.2 \mathrm{MPa}$, which was applied just to keep the sample straight during the measurement. Two microwire samples were used for the TWSME tests: one was the initial as-drawn microwire, and the other was the microwire after constant stress thermal cyclic training consisting of 16 cycles of cooling and heating across the phase transformation with an applied stress of $200 \mathrm{MPa}$.

\section{Results}

The $\mathrm{Ni}_{55} \mathrm{Mn}_{20} \mathrm{Fe}_{4} \mathrm{Ga}_{21}$ (at.\%) microwires with diameters of $100-150 \mu \mathrm{m}$ (see Supplementary Fig. S1 for the photograph and scanning electron microscopy image) were prepared by the Taylor-Ulitovsky method ${ }^{25,26}$. The microwires were tested in the as-drawn state. Energy dispersive spectroscopy (EDS) mapping indicates the 
composition homogeneity of the microwire (see Supplementary Fig. S2). DSC measurements (see Supplementary Fig. S3) reveal a reversible martensitic transformation in the microwire, with martensitic and austenitic transformation start and finish temperatures $\left(M_{\mathrm{s}}, M_{\mathrm{f}}, A_{\mathrm{s}}\right.$ and $\left.A_{\mathrm{f}}\right)$ of $197,188,219$, and $228^{\circ} \mathrm{C}$, respectively. These transformation temperatures are well above $100{ }^{\circ} \mathrm{C}$, indicating that this microwire can be classified as an HTSMA. The XRD measurements at room temperature (see Supplementary Fig. S4) show that the martensite has a tetragonal nonmodulated (NM) structure (space group $14 / \mathrm{mmm}$, No. 139 ) with lattice parameters of $a_{\mathrm{NM}}=3.810 \AA$ and $c_{\mathrm{NM}}=$ $6.624 \AA$. TEM observation reveals a martensitic microstructure (see Supplementary Fig. S5a) at room temperature, and the selected area electron diffraction (SAED) pattern (Supplementary Fig. S5b) can be well indexed according to the NM structure of martensite, as determined from the XRD measurement.

EBSD measurements at room temperature (see Supplementary Fig. S6a) demonstrate that there are several colonies of martensite in the microwire, and each colony consists of two martensitic variants that are alternately distributed. The orientations of the initial austenite grains are calculated from the orientations of the two martensitic variants existing in each colony according to the Pitsch orientation relationship ${ }^{27,28}$ (the calculation procedure is described in the Supplementary Information, Supplementary Note S1). As seen from the orientation map for the high-temperature austenite (Supplementary Fig. S6b), there are only a few austenite grains in the microwire. Each grain spans the entire cross-section of the microwire, and there are no triple junctions present; the total surface area is larger than the total grain boundary area. This confirms the oligocrystalline structure with bamboolike grains.

To examine the superelasticity, tensile stress-strain curves (Fig. 1) were measured during loading and unloading at different constant temperatures above the austenitic transformation finish temperature $A_{\mathrm{f}}$. Remarkably, the microwire exhibits superb high-temperature superelasticity at elevated temperatures of $270-480^{\circ} \mathrm{C}$ (Fig. 1). The determination of the recoverable strain $\varepsilon_{\text {rec }}$ and irrecoverable strain $\varepsilon_{\text {irr }}$ is illustrated on the typical stress-strain curve measured at $450^{\circ} \mathrm{C}$ in Supplementary Fig. S7. As seen from Fig. 1, in the temperature range of $270-420^{\circ} \mathrm{C}$, the microwire shows almost perfect superelasticity with negligible irrecoverable strain $\varepsilon_{\text {irr }}$, and the recoverable strain $\varepsilon_{\text {rec }}$ is as high as $15.0 \%$. When the temperature is increased to above $450{ }^{\circ} \mathrm{C}$, an irrecoverable strain $\varepsilon_{\text {irr }}$ appears owing to the occurrence of plastic deformation by dislocation slip, and it is $0.5 \%$ and $1.0 \%$ at 450 and $480^{\circ} \mathrm{C}$, respectively. The recoverable strain $\varepsilon_{\text {rec }}$ at $450^{\circ} \mathrm{C}$ and $480^{\circ} \mathrm{C}$ is 12.9 and $12.4 \%$, respectively (Fig. 1), which are still very high $\varepsilon_{\text {rec }}$ values. Notably, even at high

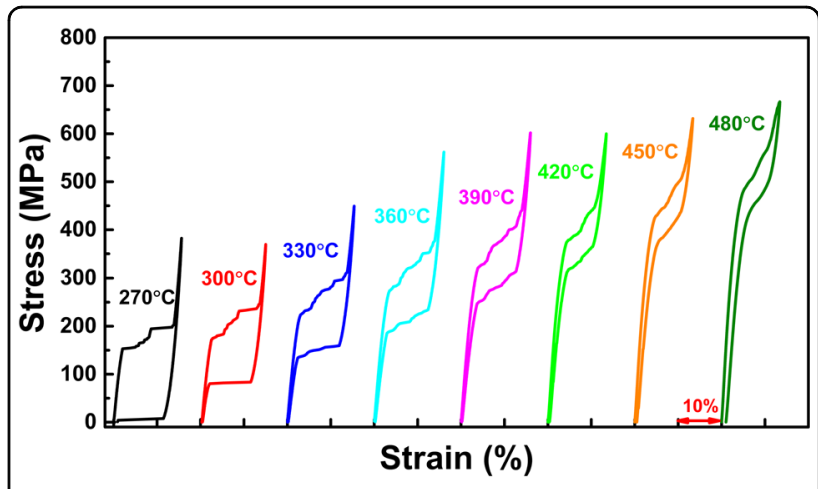

Fig. 1 High-temperature tensile superelasticity. Stress-strain curves measured at different temperatures from $270{ }^{\circ} \mathrm{C}$ to $480^{\circ} \mathrm{C}$.

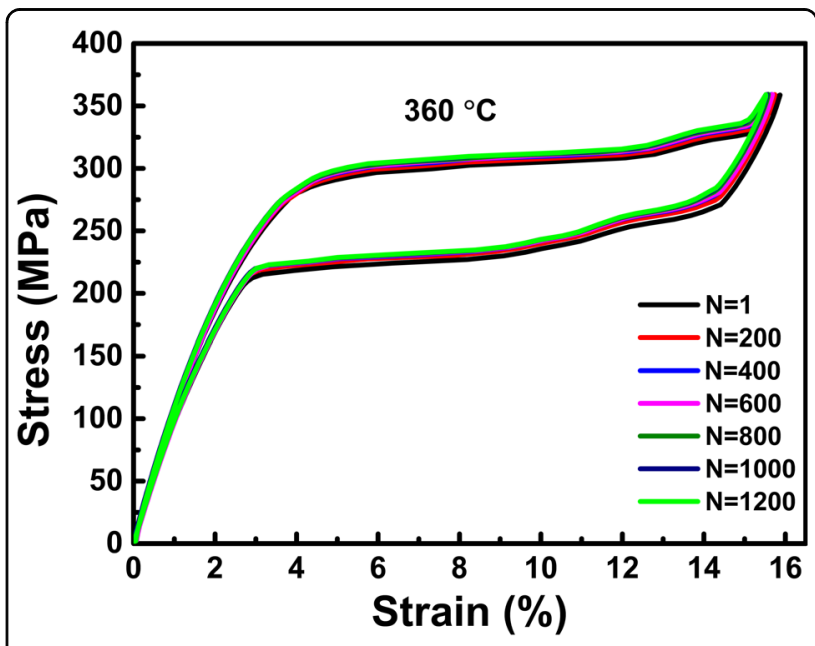

Fig. 2 Cyclic stability of the superelasticity at $360^{\circ} \mathrm{C}$, as examined by measuring the tensile stress-strain curves during 1200 cycles of loading and unloading. Only the curves measured during the 1st, 200th, 400th, 600th, 800th, 1000th, and 1200th cycles are displayed.

temperatures above $400^{\circ} \mathrm{C}$, the microwire still shows superb superelasticity with a large recoverable strain. This is in sharp contrast with existing HTSMAs that show significant functional degradation and rarely display satisfactory superelasticity at temperatures above $400^{\circ} \mathrm{C}^{2,4}$.

The cycling stability of the high-temperature superelasticity was evaluated by measuring the stress-strain curves during cyclic loading and unloading. The stress-strain curves measured at $360^{\circ} \mathrm{C}$ during 1200 cycles of loading and unloading are displayed in Fig. 2 as an example. Clearly, the curves measured during different cycles nearly overlap with each other, indicating that the superelasticity shows superior cycling stability.

The one-way SME under a biased stress was studied by measuring the strain-temperature curve during constant 


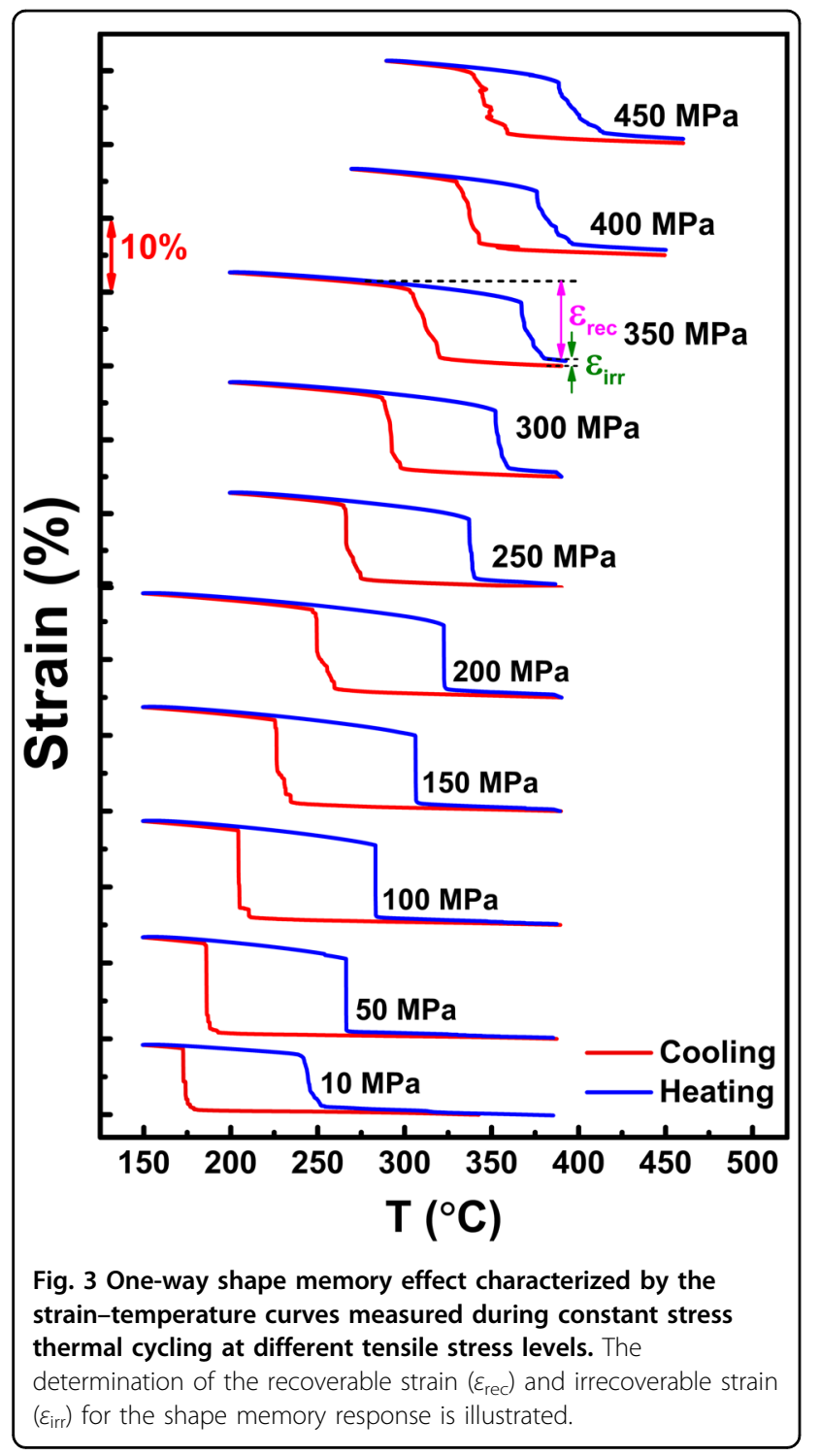

stress thermal cycling across phase transformation. Figure 3 shows the strain-temperature curves measured at different tensile stress levels. Distinctly, the microwire exhibits perfect SME at stress levels below $200 \mathrm{MPa}$, and the strain associated with martensitic transformation can be fully recovered after the cooling-heating cycle. The recoverable strain $\varepsilon_{\text {rec }}$ of SME, i.e., the shape memory strain, increases as the stress is increased from 10 to $100 \mathrm{MPa}$ due to the increased amount of preferentially oriented martensitic variants. It then plateaus as the stress is further increased from 150 to $200 \mathrm{MPa}$. The shape memory strain under $200 \mathrm{MPa}$ is as high as $13.0 \%$, which is the highest shape memory strain ever achieved in shape memory alloys. It is worth noting that even at a low stress of $10 \mathrm{MPa}$, a large shape memory strain of $9.0 \%$ can be obtained.
When the stress level is higher than $250 \mathrm{MPa}$, irrecoverable strain $\varepsilon_{\text {irr }}$ emerges due to plastic deformation. The irrecoverable strain $\varepsilon_{\text {irr }}$ is $0.5 \%$, and the shape memory strain is $11.7 \%$ at $250 \mathrm{MPa}$. The irrecoverable strain $\varepsilon_{\text {irr }}$ increases slightly as the stress is increased further and becomes $0.8 \%$ at $450 \mathrm{MPa}$. Remarkably, even at a high stress of $450 \mathrm{MPa}$, a large shape memory strain of $9.9 \%$ can still be obtained (Fig. 3). This is beneficial for achieving a large work output, which is of great importance for the compact, efficient actuation applications of HTSMAs.

The work output is a key indicator for actuation applications and is usually defined as the product of the applied stress $\sigma$ and the recoverable strain $\varepsilon_{\text {rec }}{ }^{29,30}$. As seen from Supplementary Fig. S8, the work output of the microwire increases monotonously as the applied stress is increased. When the applied stress is $450 \mathrm{MPa}$, the work output reaches a high value of $44.6 \mathrm{~J} / \mathrm{cm}^{3}$. This is much higher than the maximum value $\left(\sim 35 \mathrm{~J} / \mathrm{cm}^{3}\right)$ reported in shape memory alloys ${ }^{31}$. Notably, this high work output is obtained at high temperatures above $300^{\circ} \mathrm{C}$, which is in stark contrast with the work output of $\mathrm{Ti}-\mathrm{Ni}-(\mathrm{Pt} / \mathrm{Pd} / \mathrm{Au} /$ Hf) HTSMAs, which shows a sharp decline beyond $300^{\circ} \mathrm{C}^{2,4}$. A high work output is crucial for a compact actuator design.

The TWSME was examined by measuring the strain change during cooling and heating across phase transformation at a very low stress of $0.2 \mathrm{MPa}$. Both the as-drawn microwire without any thermomechanical history and the trained microwire subjected to 16 cycles of cooling and heating across the phase transformation at $200 \mathrm{MPa}$ were tested. As seen from the strain-temperature curves in Fig. 4a, the as-drawn microwire shows a remarkable TWSME with a large two-way shape memory strain $\varepsilon_{\mathrm{TW}}$ of $4.5 \%$. Noticeably, after training, the two-way shape memory strain $\varepsilon_{\mathrm{TW}}$ significantly increases to a large value of $6.3 \%$ (Fig. 4a). Thus, a large TWSME is achieved in the trained microwire. It is worth mentioning that the thermal hysteresis decreases after training (Fig. 4a), which may be attributed to the increased fraction of the preferably selected martensitic variants after training, leading to reduced interactions between the martensitic variant interfaces and between the austenite-martensite interfaces, thus reducing energy dissipation. To check whether such a TWSME is reproducible, we measured the strain-temperature curves of the trained microwire during five consecutive cycles of cooling and heating at $0.2 \mathrm{MPa}$. As seen from Fig. $4 \mathrm{~b}$, the $M_{\mathrm{s}}$ of the trained microwire increases slightly by $1.6^{\circ} \mathrm{C}$ during the first two cycles, while $A_{\mathrm{s}}$ and $A_{\mathrm{f}}$ remain unchanged. Starting from the second cycle, the curves measured during all the following cycles overlap well, suggesting the good reproducibility of the TWSME. 


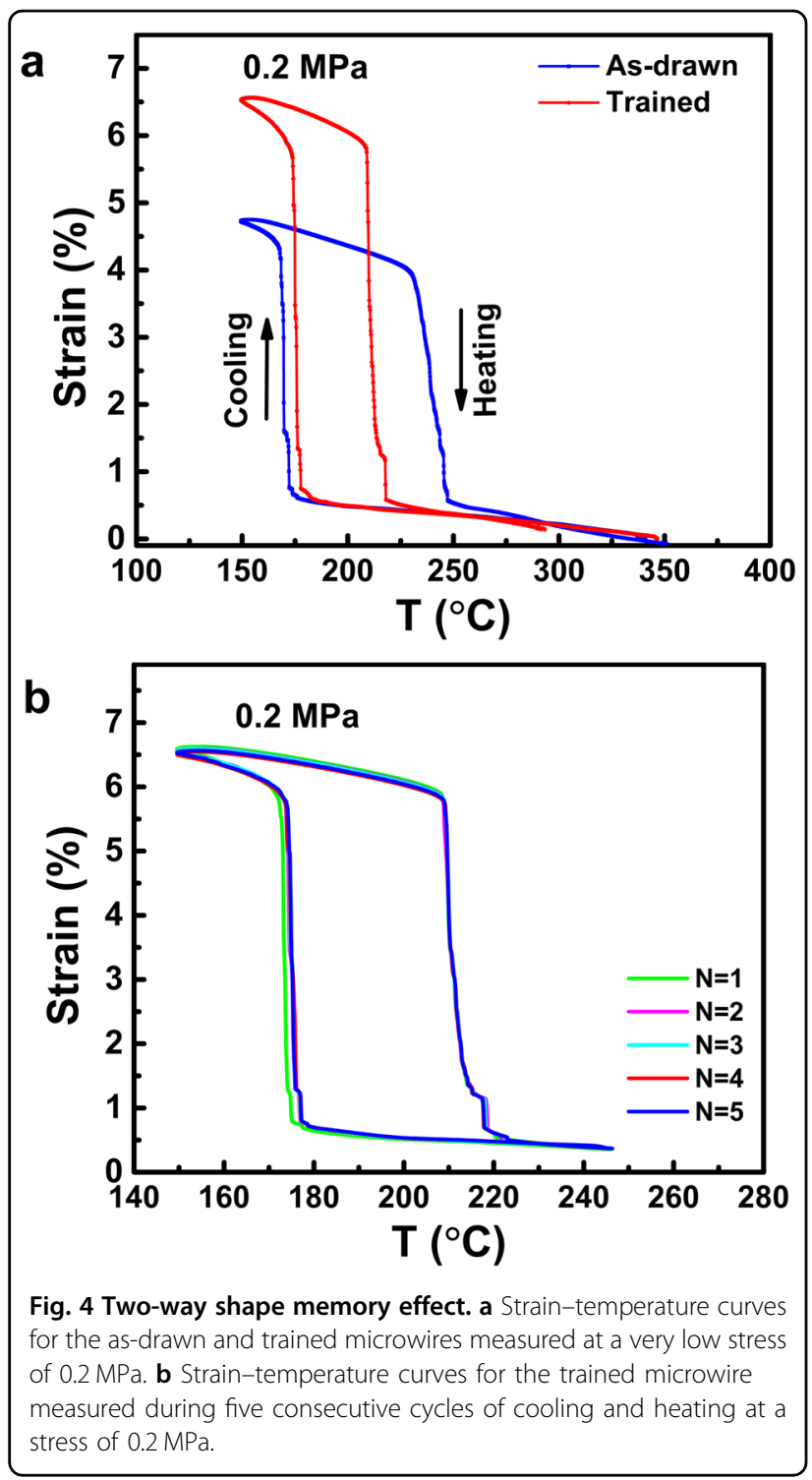

\section{Discussion}

To compare with other materials, Fig. 5 shows the hightemperature superelasticity and SME of the present microwire (denoted by "This work") and other typical HTSMAs. Clearly, the present microwire exhibits the highest recoverable strain $\varepsilon_{\text {rec }}$ of superelasticity among the HTSMAs (Fig. 5a). In fact, the recoverable strain $\varepsilon_{\text {rec }}$ of this microwire, which is as high as $15.0 \%$, is three times that of the archetypal $\mathrm{Ti}-\mathrm{Ni}-(\mathrm{Pt} / \mathrm{Pd} / \mathrm{Au} / \mathrm{Hf})$ HTSMAs. Furthermore, the temperature region of superelasticity of this microwire extends to elevated temperatures of up to $480^{\circ} \mathrm{C}$. As is well known for HTSMAs, their superelasticity deteriorates rapidly when the temperature is increased to above
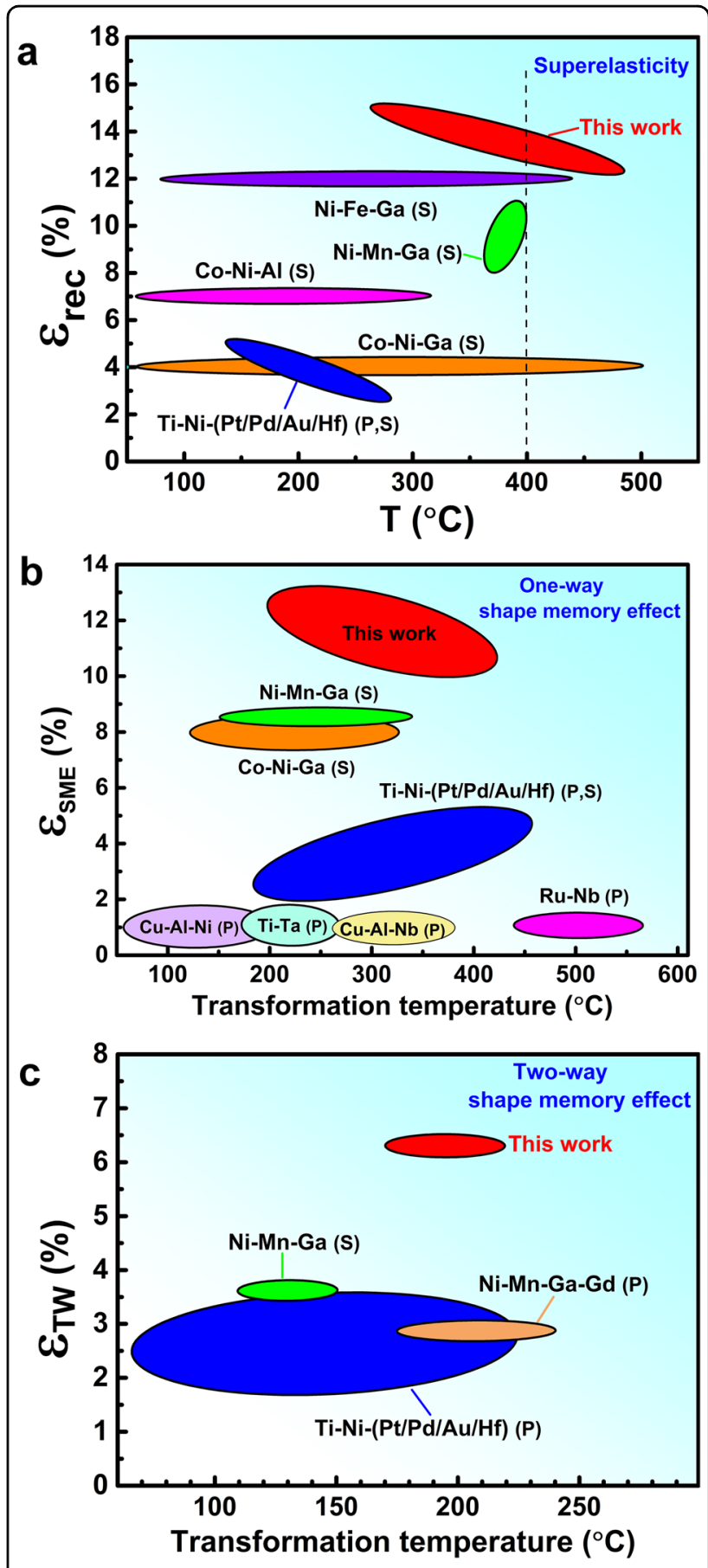

Fig. 5 Comparison of the high-temperature superelasticity and shape memory effect of the present microwire with other typical HTSMAs. The " $\mathrm{S}$ " and " $\mathrm{P}$ " in the brackets denote single crystals and polycrystals, respectively. a Recoverable strain $\left(\varepsilon_{\text {rec }}\right)$ of superelasticity plotted as a function of the operating temperature $(T)$. $\mathbf{b}$ Shape memory strain $\left(\varepsilon_{S M E}\right)$ plotted as a function of the transformation temperature under stress. c Two-way shape memory strain $\left(\varepsilon_{\mathrm{TW}}\right)$ plotted as a function of the transformation temperature. 
$400^{\circ} \mathrm{C}^{2,4}$, and it is a great challenge to obtain satisfactory superelasticity at temperatures higher than $400^{\circ} \mathrm{C}$. Here, superb superelasticity with a large recoverable strain of $12.4-13.1 \%$ is achieved in the high temperature region of $420^{\circ} \mathrm{C}$ up to $480^{\circ} \mathrm{C}$ (Figs. 1 and $5 \mathrm{a}$ ), showing that this microwire has high potential for application as an intelligent component at elevated temperatures.

As indicated in Fig. 5b, the present microwire exhibits the largest shape memory strain $\varepsilon_{\mathrm{SME}}$ among the HTSMAs. The shape memory strain $\varepsilon_{\mathrm{SME}}$ of this microwire reaches a value of $13.0 \%$, which is more than twice that of archetypal $\mathrm{Ti}-\mathrm{Ni}-(\mathrm{Pt} / \mathrm{Pd} / \mathrm{Au} / \mathrm{Hf})$ HTSMAs. Actually, this is also the largest shape memory strain among all shape memory alloys (including conventional shape memory alloys and HTSMAs). A large shape memory strain is beneficial for achieving a large stroke in actuation applications. Furthermore, the present microwire displays a remarkable TWSME with a large two-way shape memory strain $\left(\varepsilon_{\mathrm{TW}}\right)$ of $6.3 \%$, which is much higher than that of other HTSMAs (Fig. 5c). The utilization of such a large TWSME could enable the HTSMA-based actuators to operate without the requirement of a bias force to reset actuation ${ }^{32}$, greatly simplifying the design and reducing maintenance costs. As demonstrated above, the present microwire possesses superb tensile superelasticity, extraordinary one-way SME and remarkable TWSME. To our knowledge, such exceptional comprehensive properties have never been achieved in a single material. Furthermore, this microwire does not contain expensive elements, can be easily fabricated by rapid continuous wire drawing without incurring high costs, and does not require post heat treatments. The outstanding functional properties, as well as the abovementioned cost effectiveness, confer this microwire tremendous potential for high-temperature actuation, sensing, and energy conversion applications, especially in miniature systems concomitant with the ongoing miniaturization and multifunctionality trend of intelligent devices ${ }^{33}$.

Both the recoverable strain of superelasticity and the shape memory strain originates from the strain associated with the martensitic transformation ${ }^{34}$. To interpret the large recoverable strain of superelasticity and the large shape memory strain in the microwire, we performed theoretical calculations of the transformation strain based on energyminimization theory ${ }^{35,36}$. First, we calculated the orientations of the initial austenite grains from the orientations of the two martensitic variants in each initial grain (Supplementary Fig. S6a) according to the Pitsch orientation relationship $^{27,28}$ (see Supplementary Note S1 for the calculation procedure and Supplementary Fig. S6b for the orientation map of austenite) and determined the crystallographic directions that are parallel to the wire axis (which is the loading direction) for the different austenite grains. Then, we calculated the maximum theoretical transformation strain under tension in different directions (Supplementary
Fig. S6c) and obtained the transformation strain along the loading direction for each austenite grain (see Supplementary Note S1 for the calculation procedure). It is revealed that all the austenite grains have favorable orientations for attaining a large transformation strain, and the theoretically calculated transformation strain is consistent with the large recoverable strain of superelasticity and large shape memory strain that were experimentally determined (see Supplementary Note S1 for details). The oligocrystalline structure suppresses intergranular fracture, significantly enhancing the mechanical properties, and the favorable grain orientations contribute to the large transformation strain along the loading direction. Thus, the oligocrystalline structure and the favorable grain orientations account for the large superelasticity and large shape memory effect.

\section{Conclusions}

In summary, we used the strategy of creating an oligocrystalline structure to develop a high-performance hightemperature shape memory microwire. This microwire shows an exceptional combination of superb hightemperature superelasticity with a large recoverable strain of up to $15 \%$ (three times that of archetypal $\mathrm{Ti}-\mathrm{Ni}$ $(\mathrm{Pt} / \mathrm{Pd} / \mathrm{Au} / \mathrm{Hf}) \mathrm{HTSMAs}$ ) at elevated temperatures from $270{ }^{\circ} \mathrm{C}$ up to $480^{\circ} \mathrm{C}$, extraordinary one-way SME with a maximum shape memory strain of $13 \%$ (more than twice that of $\mathrm{Ti}-\mathrm{Ni}-(\mathrm{Pt} / \mathrm{Pd} / \mathrm{Au} / \mathrm{Hf}) \mathrm{HTSMAs})$ and remarkable TWSME with a huge recoverable strain of $6.3 \%$, as well as being inexpensive and easy to fabricate. These outstanding comprehensive properties endow the present microwire with tremendous potential for hightemperature actuation, sensing, and energy conversion applications. In particular, by virtue of its small size and high work output, the present microwire is extremely suitable for applications in miniature intelligent devices, such as high-temperature MEMS, which have attracted increasing attention in the information era ${ }^{37}$. Moreover, we believe that the present strategy is applicable to a wide range of brittle phase-transforming alloys to achieve superb functional properties at high temperatures.

\footnotetext{
Acknowledgements

Financial support from the National Natural Science Foundation of China (Nos. 51731005, 52031005, and 52171172), the Fundamental Research Funds for the Central Universities (Grant No. FRF-TP-18-008C1) and the State Key Laboratory for Advanced Metals and Materials (Grant No. 2021Z-17) is gratefully acknowledged. This work is also supported by the Funds for Creative Research Groups of China (No. 51921001).

\section{Author details}

${ }^{1}$ Beijing Advanced Innovation Center for Materials Genome Engineering, State Key Laboratory for Advanced Metals and Materials, University of Science and Technology Beijing, Beijing 100083, China. ${ }^{2}$ X-ray Science Division, Argonne National Laboratory, Argonne, IL 60439, USA. ${ }^{3}$ Department of Physics, City University of Hong Kong, Kowloon, Hong Kong, China. ${ }^{4}$ Key Laboratory for Anisotropy and Texture of Materials (Ministry of Education), Northeastern University, Shenyang 110819, China. ${ }^{5}$ School of Materials Science and Engineering, Harbin Institute of Technology, Harbin 150001, China
} 


\section{Author contributions}

D.C. designed the study. Z.C. performed the SEM and EBSD experiments. Y.R. and Z.C. performed the diffraction experiments and analyzed the related data. Y.Z., Z.C., and L.Y. performed the TEM observations. Z.C. and H.Y. performed the calculations and interpreted the related data. Z.C., C.S., S.H.L., Y.C., S.W.L., and L.W. carried out the mechanical tests and analyzed the related results. C.Z. performed the EDS measurements. D.C. and Y.W. supervised the project. D.C. and Z.C. wrote the manuscript. All authors discussed the results and commented on the manuscript.

\section{Conflict of interest}

The authors declare no conflict of interest.

\section{Publisher's note}

Springer Nature remains neutral with regard to jurisdictional claims in published maps and institutional affiliations.

Supplementary information The online version contains supplementary material available at https://doi.org/10.1038/s41427-022-00367-7.

Received: 25 November 2021 Revised: 14 January 2022 Accepted: 20 January 2022.

Published online: 25 February 2022

\section{References}

1. Dye, D. Towards practical actuators. Nat. Mater. 14, 760-761 (2015).

2. Van Humbeeck, J. Shape memory alloys with high transformation temperatures. Mater. Res. Bull. 47, 2966-2968 (2012).

3. Xia, J. et al. Iron-based superelastic alloys with near-constant critical stress temperature dependence. Science 369, 855-858 (2020).

4. Ma, J., Karaman, I. \& Noebe, R. D. High temperature shape memory alloys. Int. Mater. Rev. 55, 257-315 (2011)

5. Niendorf, T. et al. Martensite aging-Avenue to new high temperature shape memory alloys. Acta Mater. 89, 298-304 (2015).

6. Salje, E. K. H. Ferroelastic materials. Annu. Rev. Mater. Res. 42, 265-283 (2012).

7. Manzoni, A. M. et al. Constrained hierarchical twinning in Ru-based high temperature shape memory alloys. Acta Mater. 111, 283-296 (2016).

8. Shastry, V. V. et al. Combining indentation and diffusion couple techniques for combinatorial discovery of high temperature shape memory alloys. Acta Mater. 61, 5735-5742 (2013).

9. Zarnetta, R. et al. Identification of quaternary shape memory alloys with near -zero thermal hysteresis and unprecedented functional stability. Adv. Funct. Mater. 20, 1917-1923 (2010).

10. Kireeva, I. V. et al. Effect of oriented $\gamma^{\prime}$ precipitates on shape memory effect and superelasticity in Co-Ni-Ga single crystals. Acta Mater. 68, 127-139 (2014).

11. Pérez-Checa, A. et al. Role of Fe addition in Ni-Mn-Ga-Co-Cu-Fe ferromagnetic shape memory alloys for high-temperature magnetic actuation. Acta Mater. 196, 549-555 (2020).

12. Elahinia, M. et al. Additive manufacturing of NiTiHf high temperature shape memory alloy. Scr. Mater. 145, 90-94 (2018).

13. Buenconsejo, P. J. S., Kim, H. Y. \& Miyazaki, S. Novel $\beta$-TiTaAl alloys with excellent cold workability and a stable high-temperature shape memory effect. Scr. Mater. 64, 1114-1117 (2011).

14. $\mathrm{Yu}$, T. et al. $\mathrm{H}$-phase precipitation and its effects on martensitic transformation in NiTi-Hf high-temperature shape memory alloys. Acta Mater. 208, 116651 (2021).
15. L'vov, V. A., Kosogor, A., Barandiaran, J. M. \& Chernenko, V. A. Destabilization of $\mathrm{Ni}-\mathrm{Mn}-\mathrm{Ga}$ martensite: Experiment and theory. Acta Mater. 60, 1587-1593 (2012).

16. Li, $Y$., Xin, $Y$, Chai, L, Ma, $Y$. \& Xu, H. Microstructures and shape memon characteristics of dual-phase Co-Ni-Ga high-temperature shape memory alloys. Acta Mater. 58, 3655-3663 (2010).

17. Song, Y., Chen, X., Dabade, V., Shield, T. W. \& James, R. D. Enhanced reversibility and unusual microstructure of a phase-transforming material. Nature $\mathbf{5 0 2}$ 85-88 (2013).

18. Chluba, C. et al. Ultralow-fatigue shape memory alloy films. Science $\mathbf{3 4 8}$ 1004-1007 (2015)

19. Ogawa, Y., Ando, D., Sutou, Y. \& Koike, J. A lightweight shape-memory magnesium alloy. Science 353, 368-370 (2016).

20. Liu, J., Gottschall, T., Skokov, K. P., Moore, J. D. \& Gutfleisch, O. Giant magnetocaloric effect driven by structural transitions. Nat. Mater. 11, 620-626 (2012)

21. Mañosa, L. \& Planes, A. Materials with giant mechanocaloric effects: Cooling by strength. Adv. Mater. 29, 1603607 (2017).

22. Lai, A., Du, Z. H., Gan, C. L. \& Schuh, C. A. Shape memory and superelastic ceramics at small scales. Science 341, 1505-1508 (2013).

23. Ueland, S. M., Chen, Y. \& Schuh, C. A. Oligocrystalline shape memory alloys. Adv. Funct. Mater. 22, 2094-2099 (2012).

24. Chmielus, M., Zhang, X. X., Witherspoon, C., Dunand, D. C. \& Müllner, P. Giant magnetic-field-induced strains in polycrystalline $\mathrm{Ni}-\mathrm{Mn}-\mathrm{Ga}$ foams. Nat. Mater. 8, 863-866 (2009).

25. Chiriac, H. \& Óvári, T. A. Amorphous glass-covered magnetic wires: Preparation, properties, applications. Prog. Mater. Sci. 40, 333-407 (1996).

26. Vázquez, M., Chiriac, H., Zhukov, A., Panina, L. \& Uchiyama, T. On the state-ofthe-art in magnetic microwires and expected trends for scientific and technological studies. Phys. Status Solidi A 208, 493-501 (2011).

27. Cong, D. Y. et al. Experiment and theoretical prediction of martensitic transformation crystallography in a $\mathrm{Ni}-\mathrm{Mn}-\mathrm{Ga}$ ferromagnetic shape memory alloy. Acta Mater. 55, 4731-4740 (2007).

28. Yan, H. L., Zhang, Y. D., Esling, C., Zhao, X. \& Zuo, L. Determination of strain path during martensitic transformation in materials with two possible transformation orientation relationships from variant self-organization. Acta Mater. 202, 112-123 (2021).

29. Pagounis, E., Szczerba, M. J., Chulist, R. \& Laufenberg, M. Large magnetic fieldinduced work output in a NiMnGa seven-layered modulated martensite. Appl. Phys. Lett. 107, 152407 (2015).

30. Ganor, Y., Shilo, D., Shield, T. W. \& James, R. D. Breaching the work output limitation of ferromagnetic shape memory alloys. Appl. Phys. Lett. 93, 122509 (2008).

31. Karaca, H. E. et al. Shape memory behavior of high strength NiTiHfPd polycrystalline alloys. Acta Mater. 61, 5036-5049 (2013).

32. Panchenko, E., Eftifeeva, A., Chumlyakov, Y., Gerstein, G. \& Maier, H. J. Two-way shape memory effect and thermal cycling stability in $\mathrm{CO}_{35} \mathrm{Ni}_{35} \mathrm{Al}_{30}$ single crystals by low-temperature martensite ageing. Scr. Mater. 150, 18-21 (2018).

33. Gueltig, M. et al. High-performance thermomagnetic generators based on Heusler alloy films. Adv. Energy Mater. 7, 1601879 (2016).

34. Otsuka, K. \& Ren, X. Physical metallurgy of Ti-Ni-based shape memory alloys. Prog. Mater. Sci. 50, 511-678 (2005).

35. James, R. D. \& Hane, K. F. Martensitic transformations and shape-memor materials. Acta Mater. 48, 197-222 (2000).

36. Karaca, H. E. et al. Magnetic field-induced phase transformation in NiMnColn magnetic shape-memory alloys-A new actuation mechanism with large work output. Adv. Funct. Mater. 19, 983-998 (2009).

37. Krogstad, J. A., Keimel, C. \& Hemker, K. J. Emerging materials for microelectromechanical systems at elevated temperatures. J. Mater. Res. 29, 1597-1608 (2014). 